\title{
Eosinophil peroxidase over-expression predicts the clinical outcome of patients with primary lung adenocarcinoma
}

\author{
Liang Ye1,2,\#, Hongying Wang3,\#, Huijuan Li1 ${ }^{1}$, Hongbing Liu1 ${ }^{1}$, Tangfeng Lv1, Yong Song1, ${ }^{凶}$, Fang Zhang1, ${ }^{1,}$ \\ 1. Department of Respiratory Medicine, Jinling Hospital, Nanjing Medical University, Nanjing, China \\ 2. Department of Respiratory Medicine, Nanjing First Hospital, Nanjing Medical University, Nanjing, China \\ 3. Department of Respiratory Medicine, Jinling Hospital, Southern Medical University, Nanjing 210002, China \\ \#These authors contributed equally to this work. \\ $\square$ Corresponding authors: Yong Song, Department of Respiratory Medicine, Jinling Hospital, Nanjing Medical University, No. 305 East Zhongshan Road, \\ Nanjing 210002, P. R. China. Tel: +86-025-80863591; Fax: +86-025-80863591; E-mail:yong_song6310@yahoo.com. Fang Zhang, Department of Respiratory \\ Medicine, Jinling Hospital, Nanjing Medical University, No.305 East Zhongshan Road, Nanjing 210002, P. R. China; Tel: +86-025-80863591; \\ Fax:+86-025-80863591; Email: zhangfanglab@163.com. \\ (c) Ivyspring International Publisher. This is an open access article distributed under the terms of the Creative Commons Attribution (CC BY-NC) license \\ (https:// creativecommons.org/licenses/by-nc/4.0/). See http://ivyspring.com/terms for full terms and conditions.
}

Received: 2017.12.12; Accepted: 2018.04.14; Published: 2019.01.29

\begin{abstract}
Eosinophil peroxidase (EPO), a heme protein abundantly expressed in eosinophils, involves in the catalysis of cytotoxic oxidants associated with the pathogenesis of cancer, asthma, and allergic inflammatory disorders. To date, its roles in the pathogenesis of lung cancer are still not known. We determined the expression of EPO in the lung adenocarcinoma tissues and the normal adjacent lung tissues using Real-time PCR and Western blotting analysis, respectively. Also, EPO protein expression in 90 lung adenocarcinoma (AD) samples were confirmed with immunohistochemistry (IHC) using tissue microarrays. Meanwhile, we investigated the association between EPO and the clinicopathological characteristics and disease prognosis in the pulmonary adenocarcinoma patients, which demonstrated that EPO mRNA and protein were significantly higher in lung AD tissues that those of the adjacent normal lung tissues $(\mathrm{P}<0.05)$. EPO overexpression was significantly correlated with pathologic-tumour nodes metastasen stage ( $P$-TNM stage, $P=0.017)$ and lymph node metastasis $(P=0.027)$. Patients with EPO overexpression showed shorter survival time than those with low EPO levels $(P=0.017)$, according to the Kaplan-Meier survival curve. Furthermore, a multivariate Cox regression model was utilized to analyze the prognostic factors, which indicated that $\mathrm{N}$ stage $(\mathrm{HR}=0.965,95 \% \mathrm{Cl}=0.328-1.359, \mathrm{P}=0.008), \mathrm{p}-\mathrm{TNM}$ Stage $(\mathrm{HR}=3.127,95 \% \mathrm{Cl}=2.463-5.015, \mathrm{P}=0.021)$ and high EPO protein expression $(\mathrm{HR}=3.145,95 \%$ $\mathrm{Cl}=2.016-5.519, \mathrm{P}=0.018$ ) were independent factors for the prognosis of lung $\mathrm{AD}$. In conclusion, increased EPO expression could be used as a biomarker for lung AD patients with poor prognosis.
\end{abstract}

Key words: Eosinophil peroxidase; adenocarcinoma; oxidative stress; prognosis

\section{Introduction}

Non-small-cell lung cancer (NSCLC) is considered as one the causes for cancer-associated mortality [1,2]. As the most frequent histological subtypes, squamous cell carcinoma (SCC) and adenocarcinoma account for about $30 \%$ and $50 \%$ of NSCLC cases, respectively [3]. Nowadays, surgery is still regarded as the best treatment option for early-stage NSCLC, however, many patients may present regional or distant recurrence after surgery [4,
5]. To date, most of the NSCLC cases showed poor prognosis due to metastasis and absence of curative systemic therapy. Therefore, it is urgent to develop new therapeutic options in clinical practice.

Oxidative stress, caused by the imbalance between free radicals and reactive metabolites, is reported to involve in the pathogenesis and progression of cancer [6-8]. To our best knowledge, lung is the major organ exposed continuously to 
higher oxygen and oxidant-generating environmental agents. Oxidative stress imbalance would trigger pulmonary damage and even malignancy [9]. Meanwhile, extensive studies have been performed to investigate the expression of classical antioxidants [e.g. superoxide dismutases (SODs) and peroxidase] in lung cancer $[10,11]$.

Eosinophil peroxidase (EPO), is a two-subunit protein with a modified hemeprosthetic group. The gene encoding EPO protein is localized on chromosome 17 [12]. For the protein structure, EPO shares an amino acid homology of $70 \%$ compared to the neutrophil myeloperoxidase (MPO) [13] that shows a genetic link with the risk for developing cancer [14, 15]. Similarly, EPO is also linked to cell proliferation and differentiation [16]. In tumor tissues, the majority of EPO is derived from EOS [17], however, our knowledge on the expression of EPO in tumors is still limited. Thus, we aim to determine the expression of EPO protein in human lung adenocarcinoma (AD) using tissue microarrays (TMAs). Meanwhile, we investigated the correlation between EPO level and clinicopathologic features.

\section{Materials and methods}

\section{Sample collection}

NSCLC tissue and paired adjacent normal lung tissues were obtained from 30 cases received surgical resection in Jinling Clinical Medical College of Nanjing University School from March 2015 to November 2015. After surgery, the samples were stored in liquid nitrogen. NSCLC was confirmed using histopathological methods. Patients received adjuvant therapy before surgery were excluded from the study. Each patient signed the informed consent. Study protocols were approved by the Ethical Committee of Jinling Clinical Medical College of Nanjing University School.

\section{TMAs}

TMAs for the lung AD patients $(n=90)$ and paired adjacent normal tissues were used to evaluate EPO expression, by using commercial kit with strict adhesion to the manufacturer's instructions (HLug-Ade180Sur-01; Shanghai Outdo Biotech, Shanghai, China). Antigen retrieval was performed in the presence of a high pressure for $5 \mathrm{~min}$. The sections were incubated with the Rabbit polyclonal Anti-EPO antibody (HPA026631; Sigma-Aldrich, CA, USA) at $4^{\circ} \mathrm{C}$ overnight. Afterwards, the sections incubated with PBS served as negative control. The staining was evaluated based on a 0-3 scale system by two pathologists blinded to the study as follows: 0, negative staining; 1 , weak staining; 2 , medium staining; 3 , strong staining. The scoring of the staining extent, also defined as the percentage of positive staining areas, was given based on a scale of $0(0 \%), 1$ $(1-25 \%), 2(26-50 \%), 3(51-75 \%)$ and $4(76-100 \%)$, respectively. The overall protein expression score was in a range of $0-12$, which was generated by the multiply of the positivity score and the intensity. A score of $\leq 4$ was defined as low expression, while a score of $>4$ was defined as high expression.

\section{Cell culture}

Cell lines, including 4 cell lines of lung AD (i.e. SPC-A1, A549, PC-9 and NCI-H1299), 1human bronchial epithelial cell line (HBE) and 1cell line of lung squamous carcinomas (NCI-H1703), were provided by the Institute of Bio-chemistry and Cell Biology of the Chinese Academy of Sciences (Shanghai, China). SPC-A1and HBE cells were cultured in DMEM medium (Invitrogen, MI, USA) supplemented with fetal bovine serum (FBS, 10\%), 100 $\mathrm{mg} / \mathrm{ml}$ streptomycin, and $100 \mathrm{U} / \mathrm{ml}$ penicillin (Invitrogen, CA, USA). The other cells (i.e. A549, PC-9, NCI-H1703 and NCI-H1299) were cultured in RPMI 1640 medium at $37^{\circ} \mathrm{C}$ in $5 \% \mathrm{CO}_{2}$.

\section{Real-time PCR}

Total RNA extraction from cell lines or tissues were performed using TriZol reagent (Invitrogen, CA, USA). PrimeScript RT reagent Kit (Invitrogen, CA, USA) was used for the cDNA synthesis with random primers. Real-Time PCR was carried out using SYBR on an ABI 7500 system (Applied Biosystems, MI, USA). Primers for EPO were designed as follows: 5 -caggatgccatgtgagtgga-3, and 5'-gctaagctgtgccaaatt cc- $3^{\prime}$. The $\beta$-actin served as internal standard (5'-gaaatcgtgcgtgacattaa- $3^{\prime}$, and 5'-aaggaaggctggaaga gtg- $\left.3^{\prime}\right)$. PCR amplification conditions were as follows: $95^{\circ} \mathrm{C}$ for $30 \mathrm{sec} ; 40 \mathrm{cycles}$ of $95^{\circ} \mathrm{C}$ for $5 \mathrm{sec}$ and $60^{\circ} \mathrm{C}$ for $35 \mathrm{sec}$. The relative quantification of EPO mRNA expression was calculated according to the conventional 2- $-\Delta \mathrm{CT}$ method.

\section{Western blotting analysis}

The protein was extracted using lysis buffer containing RIPA, protease inhibitor and PMSF. The protein concentration was measured using BCA method. Protein $(40 \mu \mathrm{g})$ were electrophoresed on a 10\% SDS-PAGE, followed by transferring onto a nitrocellulose membrane. Subsequently, the mixture was incubated with EPO antibody (1:500, category No. A81365; Sigma-Aldrich, CA, USA). The density of protein band was evaluated using a densitometry using the Quantity One Software (Bio-Rad, CA, USA). The membrane probed for $\beta$-actin served as internal control. 


\section{Statistical analysis}

Data analysis was conducted using the SPSS 18.0 Software. Chi-square test was conducted to investigate the association between the EPO and clinicopathologic parameters. Kaplan-Meier method was used for the plotting of the cumulative overall survival (OS) curves. Univariate analysis was conducted to analyze the relationship between each of the variables and survival. Multivariate Cox proportional hazards model was utilized to screen the independent variables that could be used for the prediction of patients' survival. $P<0.05$ was considered to be statistically significant.

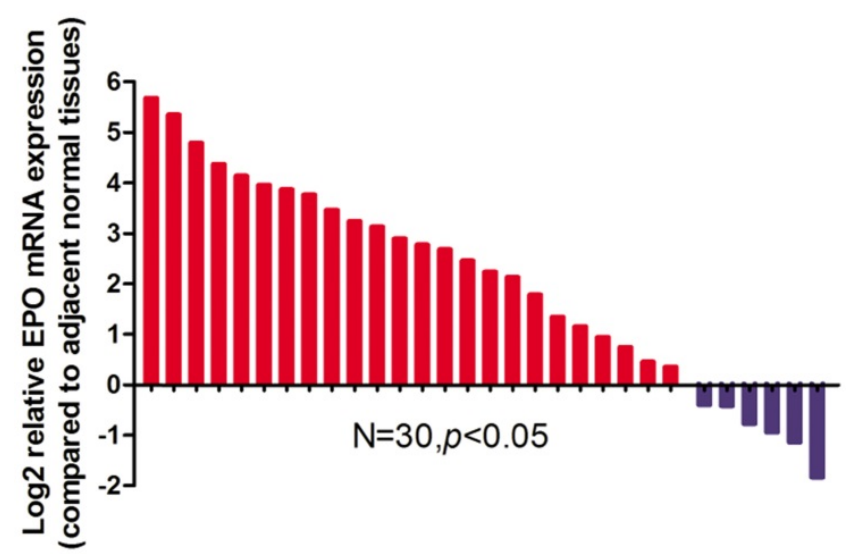

Fig. 1. Relative expression levels of EPO mRNA in NSCLC tissues and paired adjacent non-tumoral tissues $(n=30)$ by qRT-PCR. The levels of EPO in NSCLC tissues are significantly higher than those in non-tumoral tissues

\section{Results}

\section{Up-regulation of EPO expression in NSCLC tissues}

EPO expression was significantly higher in cancerous tissues compared with that of the normal adjacent tissues $(P<0.05$, Fig $\mathbf{1})$. Western blot analysis demonstrated the EPO protein was up-regulated in NSCLC tissues than that of the adjacent normal tissues (Fig 2). Additionally, EPO protein expression in the lung cancer cell lines was higher than that of normal lung samples (Fig 3).

Immunohistochemistry (IHC) analysis was used to determine the expression of EPO protein in the lung $\mathrm{AD}$ carcinoma tissues and adjacent normal tissues. EPO protein was mainly localized in cytoplasm. The representative staining for EPO immunohistochemistry were shown in Fig 4A. In normal lung tissues, no staining or weak staining was observed (Fig 4B). EPO protein expression in lung AD tissues was significantly up-regulated than that of the normal adjacent tissues $(P=0.001$, Fig 4C). Taken together, we concluded that the up-regulation of EPO may involve in the pathogenesis and progression of lung AD.

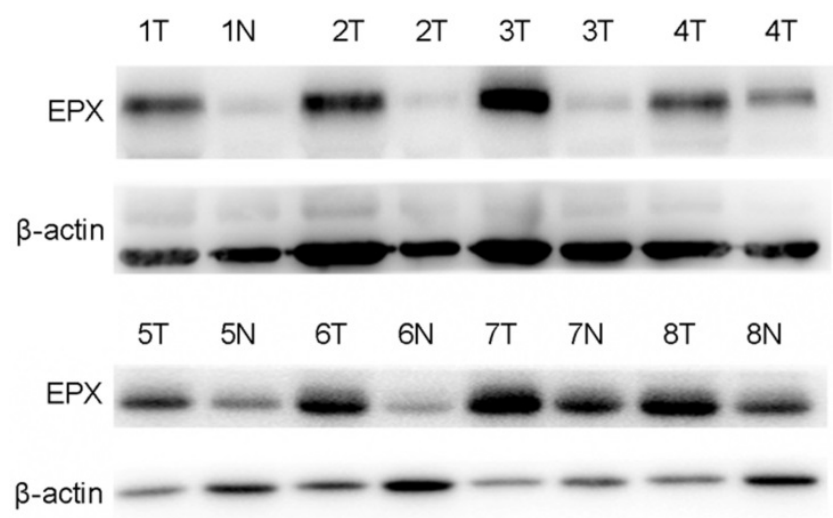

Fig. 2. Expression levels of EPO protein in 8 paired primary NSCLC tissues as determined by Western blotting

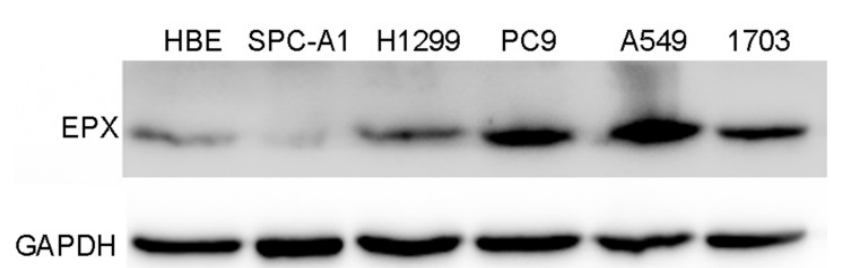

Fig. 3. Expressions of EPO detected in NSCLC cell lines (HBE, SPC-A1, H1299, PC9, A549 and $\mathrm{H} 1703)$ by Western blot analysis

\section{Relationship between EPO overexpression and clinicopathological features in lung AD patients}

Table 1 showed the relationship between EPO overexpression and clinicopathological characteristics in lung AD patients. EPO protein overexpression $(>4)$ was significantly correlated with pathologic-tumour nodes metastasen stage ( $\mathrm{p}$-TNM stage, $P=0.017$ ), as well as lymph node metastasis $(P=0.027)$. No significant correlation was noticed between EPO expression and the other clinicopathological characteristics.

Patients with overexpression of EPO protein showed a shorter survival time than those with low levels $(P=0.017$, Fig 5). Univariate analysis was used to evaluate the correlation between prognosis and other clinicopathological factors in patients with lung $\mathrm{AD}$, which revealed that male gender $(P=0.046)$, advanced $\mathrm{pT}$ status $(P=0.023)$, advanced $\mathrm{pN}$ status $(P=0.012)$, poor differentiation $(P=0.038)$, and EPO status $(P=0.014)$ were significantly associated with poor prognosis. Additionally, multivariate analysis showed that EPO status was an independent marker for predicting poorer overall survival (OS) in lung $\mathrm{AD}$ patients $(\mathrm{HR}=3.145,95 \% \mathrm{CI}=2.016-5.519, P=0.018$, Table 2). These results indicated that EPO was an independent factor for predicting the survival in lung AD patients. 


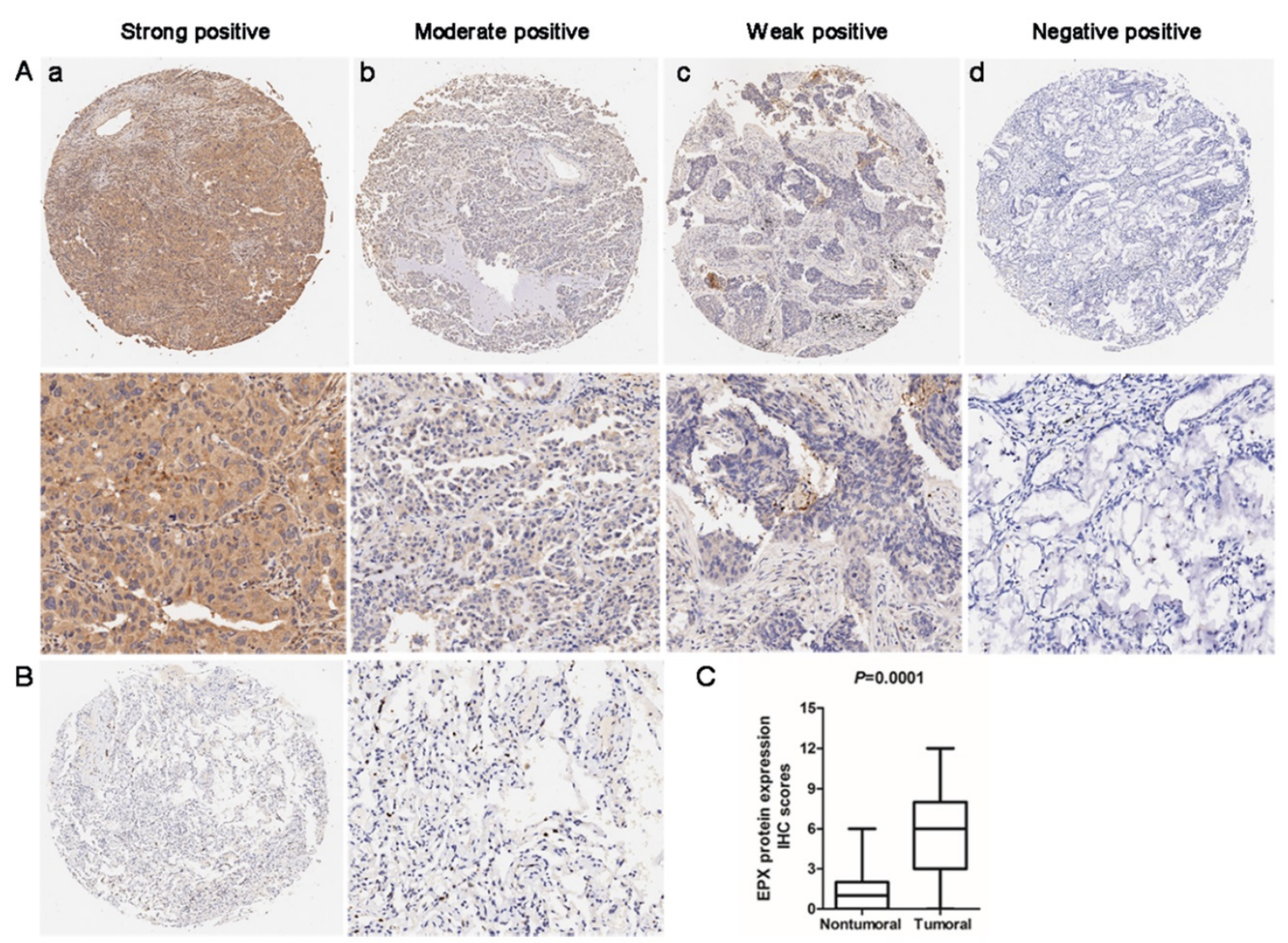

Fig. 4. Expression levels of EPO protein in 90 paired lung AD tissues and paired adjacent non-tumoral tissues by immunohistochemistry (IHC). (A) Representative examples of EPO protein expression in lung adenocarcinoma (ADC). (a) Strong-positive expression of EPO; (b) Moderately-positive expression; (c) Weak-positive expression; (d) Negative expression (B) No staining or weak positive in normal lung tissue. (C) Statistical analysis of EPO scores in lower panel.

Table 1. Correlation of EPX expression with various clinicopathological features in 90 patients with lung adenocarcinoma

\begin{tabular}{|c|c|c|c|c|}
\hline & \multirow[t]{2}{*}{ Number of patients } & \multicolumn{3}{|c|}{ EPX protein expression } \\
\hline & & Low $(\leq 4)$ & $\operatorname{High}(>4)$ & $P$ value \\
\hline All patients & 90 & 38 & 52 & \\
\hline \multicolumn{5}{|l|}{ Gender } \\
\hline Male & 49 & 21 & 28 & 0.894 \\
\hline Female & 41 & 17 & 24 & \\
\hline \multicolumn{5}{|l|}{ Age (years) } \\
\hline$<65$ & 40 & 15 & 25 & 0.417 \\
\hline$\geq 65$ & 50 & 23 & 27 & \\
\hline \multicolumn{5}{|c|}{ Size of tumour } \\
\hline$\leq 3 \mathrm{~cm}$ & 35 & 14 & 21 & 0.733 \\
\hline$>3 \mathrm{~cm}$ & 55 & 24 & 31 & \\
\hline \multicolumn{5}{|c|}{ Histology grade } \\
\hline I & 38 & 14 & 24 & 0.626 \\
\hline II & 21 & 9 & 12 & \\
\hline III & 31 & 15 & 16 & \\
\hline \multicolumn{5}{|c|}{ Lymph node metastasis $(\mathrm{pN})$} \\
\hline No & 30 & 18 & 13 & 0.027 \\
\hline N1-3 & 60 & 20 & 39 & \\
\hline \multicolumn{5}{|l|}{ TNM stage } \\
\hline I & 28 & 17 & 11 & 0.017 \\
\hline II+III & 62 & 21 & 41 & \\
\hline
\end{tabular}

\section{Discussion}

We firstly reported the expression of EPO in lung $\mathrm{AD}$ tissues. Our data demonstrated that expression of EPO mRNA and protein showed significant elevation in lung $\mathrm{AD}$ tissues than that of the paired normal tissues. Additionally, EPO over-expression could serve as an independent factor to predict the prognosis of lung cancers.

Table 2. Univariate and multivariate analyses for prognostic factors in patients with lung adenocarcinoma

\begin{tabular}{lllllll}
\hline Variable & \multicolumn{2}{l}{ Univariate } & \multicolumn{4}{l}{ Multivariate } \\
\hline & HR & $95 \% \mathrm{CI}$ & \multicolumn{1}{l}{$P$ value } & HR & $95 \% \mathrm{CI}$ & $P$ value \\
\hline Age $(\geq 65 /<65$ years) & 1.134 & $0.586-1.743$ & 0.937 & 0.963 & $0.754-1.628$ & \\
Gender (Female/Male) & 1.475 & $1.032-2.358$ & 0.046 & 1.605 & $0.918-2.895$ & 0.078 \\
Tumor size (>3 cm/ $\leq 3 \mathrm{~cm})$ & 2.246 & $1.235-4.578$ & 0.231 & 2.689 & $1.753-4.738$ & \\
Histology grade (3 vs,1+2) & 1.125 & $0.568-2.168$ & 0.038 & 1.729 & $1.016-2.746$ & 0.063 \\
N stage (N1-3/N0) & 1.068 & $0.645-1.897$ & 0.012 & 0.965 & $0.328-1.359$ & 0.008 \\
p-TNM Stage (II+III vs. I) & 2.638 & $1.273-4.389$ & 0.023 & 3.127 & $2.463-5.015$ & 0.021 \\
EPX expression (high/low) & 2.023 & $1.867-4.589$ & 0.014 & 3.145 & $2.016-5.519$ & 0.018 \\
\hline
\end{tabular}

The release of EPO is mainly associated with the activation induced by many stimuli including immunoglobulins-mediated mechanisms, surfacebound complement, as well as lipid mediators [18]. EPO is exclusively generated in mature circulating EOS, and partial of the protein were detected in neutrophils of the peripheral blood [19]. According to the previous studies, elevation of EPO may be the most valuable biomarker for eosinophil activation [20-22]. Thus, EPO was usually used as a marker for the diagnosis of asthma and other chronic inflammatory diseases. 


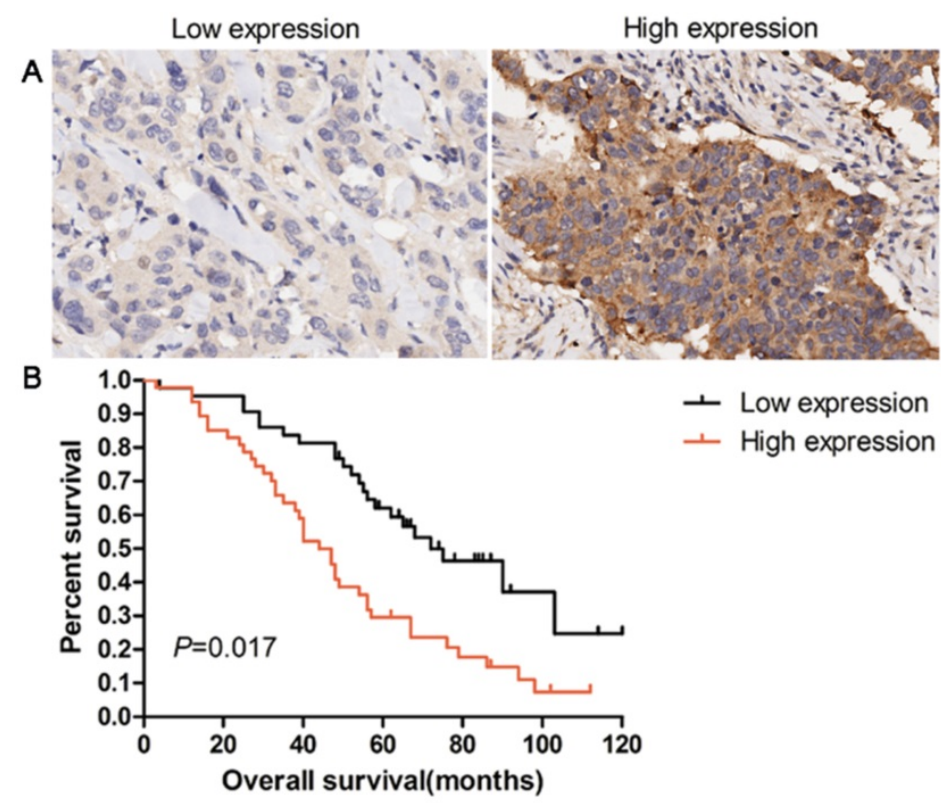

Fig. 5. Overexpression of EPO protein was associated with poor overall survival in patients with lung AD. (A) IHC staining of low expression and high expression of EPO in 90 patients with lung AD. (B) Kaplan-Meier curves for overall survival rate in 90 patients with lung AD according to the expression status of EPO. The median staining score (4 score) was served as a cut-off to divide patients into high and low EPO. Black line: patients with low EPO expression; red line: patients with high EPO expression. High EPO protein expression was significantly associated with decreased overall survival $(P=0.017$, log-rank test)

Previously, EPO was reported to involve in the pathogenesis of cancer, asthma, and allergic inflammatory disorders. In patients with renal cell adenocarcinoma, serum EPO was significantly higher before and during treatment compared to that of the controls [23]. Slatter et al. showed that EPO gene polymorphism were associated with the pathogenesis of colon and rectal cancer, indicating that oxidative stress increased the risk of colon and rectal cancer [24]. Moreover, EPO was considered to participate in the pathogenesis and development of breast cancer and lymphoma [25-27]. These studies demonstrated the roles of eosinophil degranulation-derived EPO in the pathogenesis and development of carcinoma and EPO activation may exert an oncogenic role in the progression of cancer. In our study, EPO staining was noticed in the cytoplasm of partial lung cancer cells. Then we tried to confirm that the EPO was expressed by lung cancer cells. In vitro experiments, Real-time PCR and Western blotting analysis confirmed that EPO was expressed in lung cancer cells. Therefore, we firstly demonstrated that EPO was also expressed in lung cancer cells. Besides, we also analyzed the clinical significance of EPO expression in lung AD patients, which showed a positive rate of $57.78 \%$ for EPO expression in 90 lung AD tissues. Clinicopathologic analysis indicated that EPO expression was significantly correlated with tumor size, pT classification, $\mathrm{pN}$ classification, and AJCC stage. Patients with high expression of EPO showed poorer OS compared to these with low EPO expression as revealed by Kaplan-Meier analysis.
Therefore, EPO expression could be used as an independent prognostic indicator of survival according to the Cox regression analysis. Thus, identification of EPO may be utilized as a highly promising marker for the diagnosis and prognosis of NSCLC.

To date, the mechanisms of how EPO expression involves in the progression and metastasis of cancer are still unclear. Oxidative processes have been well acknowledged to be associated with the carcinogenesis [28, 29]. Many progresses involve utility of stable markers of free radical reactions for the identification of specific mechanisms of DNA damage in vivo. Shen et al. showed that reactive brominating species formed by $\mathrm{EPO} / \mathrm{H}_{2} \mathrm{O}_{2} / \mathrm{Br}$-system of eosinophils may trigger the oxidative modification of nucleotide pools and DNA [30].In a recent study, EPO was reported to involve in the oxidization of bisulfite, which finally resulted in the formation of sulfate anion radicals. These intermediates triggered the oxidize target proteins to radicals, and then initiate the protein oxidation. All these demonstrated that EPO-dependent oxidative damage was closely associated with the tissue injury in bisulfiteexacerbated eosinophilic inflammatory disorders [31]. In addition, Walsh et al. reported that EPO could cause a sustained elevation of epidermal growth factor-2 (HER2) and the phosphorylation (at tyrosine 1248), which in turn triggered the FAK-and ERK-dependent loss of the cyclin-dependent kinase inhibitor p27kip in the nucleus. Also, it promoted the proliferation and cell-cycle progression [16].In a 
previous study, EPO was also considered as a driving force for angiogenesis. Also, it promoted cellular proliferation, invasion, migration, and stimulate angiogenesis in vitro and in vivo, respectively [32]. Moreover, EPO showed immunomodulatory effects and could inhibit the activation and proliferation of $\mathrm{T}$ lymphocytes [33] that played a vital role in the immune response. On this basis, we speculated that EPO expression in cancer cells may implicate in inhibiting anti-tumor immune response and resisting the cancer immunotherapy.

In conclusion, EPO expression was up-regulated in primary or several lung cancer cell lines. A high EPO level was strongly correlated with poor survival in patients with lung AD. EPO may serve as a new biomarker for predicting the prognosis of lung $\mathrm{AD}$, and regulation of EPO expression may provide a new target for treating lung AD. In future, more studies are required to identify the mechanisms of how EPO expression involves in the progression and metastasis of cancer.

\section{Acknowledgments}

This study was supported by the National Natural Science Foundation of China (No. 81270079 and No.81570025).

\section{Ethical approval}

All procedures performed in studies involving human participants were in accordance with the ethical standards of the Institutional Review Board of Jinling Clinical Medical College of Nanjing University School and with the 1964 Helsinki declaration and its later amendments or comparable ethical standards.

\section{Informed consent}

Informed consent was obtained from all individual participants included in the study.

\section{Competing Interests}

The authors have declared that no competing interest exists.

\section{References}

1. Siegel R, Naishadham D, Jemal A. Cancer statistics, 2012. CA: a cancer journal for clinicians. 2012;62:10-29

2. Chen W, Zheng R, Baade PD, Zhang S, Zeng H, Bray F et al. Cancer statistics in China, 2015. CA: a cancer journal for clinicians. 2016;66:115-32

3. Detterbeck FC, Boffa DJ, Tanoue LT. The new lung cancer staging system. Chest. 2009;136:260-71

4. Eberhardt WE, De Ruysscher D, Weder W, Le Pechoux C, De Leyn P, Hoffmann $\mathrm{H}$ et al. 2nd ESMO Consensus Conference in Lung Cancer: locally advanced stage III non-small-cell lung cancer. Annals of oncology : official journal of the European Society for Medical Oncology / ESMO. 2015;26:1573-88

5. Bergot E, Levallet G, Campbell K, Dubois F, Lechapt E, Zalcman G. Predictive biomarkers in patients with resected non-small cell lung cancer treated with perioperative chemotherapy. European respiratory review : an official journal of the European Respiratory Society. 2013;22:565-76
6. Reuter S, Gupta SC, Chaturvedi MM, Aggarwal BB. Oxidative stress, inflammation, and cancer: how are they linked? Free radical biology \& medicine. 2010;49:1603-16

7. Goldkorn T, Filosto S, Chung S. Lung injury and lung cancer caused by cigarette smoke-induced oxidative stress: Molecular mechanisms and therapeutic opportunities involving the ceramide-generating machinery and epidermal growth factor receptor. Antioxidants \& redox signaling. 2014;21:2149-74

8. Durackova Z. Some current insights into oxidative stress. Physiological research. 2010;59:459-69.

9. Lee SH, Choi SI, Lee JS, Kim CH, Jung WJ, Lee EJ et al. Reactive Oxygen Species Modulator 1 (Romo1) Predicts Poor Outcomes in Advanced Non-small Cell Lung Cancer Patients Treated with Platinum-Based Chemotherapy. Cancer research and treatment: official journal of Korean Cancer Association. 2017;49:141-9

10. Glasauer A, Sena LA, Diebold LP, Mazar AP, Chandel NS. Targeting SOD1 reduces experimental non-small-cell lung cancer. The Journal of clinical investigation. 2014;124:117-28

11. Lehtonen ST, Svensk AM, Soini Y, Paakko P, Hirvikoski P, Kang SW et al. Peroxiredoxins, a novel protein family in lung cancer. International journal of cancer. 2004;111:514-21

12. Forrest GL, Gonzalez B. Carbonyl reductase. Chemico-biological interactions. 2000;129:21-40

13. Ten RM, Pease LR, McKean DJ, Bell MP, Gleich GJ. Molecular cloning of the human eosinophil peroxidase. Evidence for the existence of a peroxidase multigene family. The Journal of experimental medicine. 1989;169:1757-69

14. Yoon KA, Kim JH, Gil HJ, Hwang H, Hwangbo B, Lee JS. CYP1B1, CYP1A1, $\mathrm{MPO}$, and GSTP1 polymorphisms and lung cancer risk in never-smoking Korean women. Lung cancer. 2008;60:40-6

15. Al-Salihi M, Reichert E, Fitzpatrick FA. Influence of myeloperoxidase on colon tumor occurrence in inflamed versus non-inflamed colons of $\mathrm{Apc}(\mathrm{Min} /+)$ mice. Redox biology. 2015;6:218-25

16. Walsh MT, Connell K, Sheahan AM, Gleich GJ, Costello RW. Eosinophil peroxidase signals via epidermal growth factor-2 to induce cell proliferation. American journal of respiratory cell and molecular biology. 2011;45:946-52

17. Samoszuk MK, Nguyen V, Gluzman I, Pham JH. Occult deposition of eosinophil peroxidase in a subset of human breast carcinomas. The American journal of pathology. 1996;148:701-6

18. Pereira MC, Oliveira DT, Kowalski LP. The role of eosinophils and eosinophil cationic protein in oral cancer: a review. Archives of oral biology. 2011;56:353-8

19. Rundstrom G, Jonsson A, Martensson O, Mendel-Hartvig I, Venge P. Lateral flow immunoassay using Europium (III) chelate microparticles and time-resolved fluorescence for eosinophils and neutrophils in whole blood. Clinical chemistry. 2007:53:342-8

20. Nair P, Ochkur SI, Protheroe C, Radford K, Efthimiadis A, Lee NA et al. Eosinophil peroxidase in sputum represents a unique biomarker of airway eosinophilia. Allergy. 2013;68:1177-84

21. Ochkur SI, Kim JD, Protheroe CA, Colbert D, Condjella RM, Bersoux S et al. A sensitive high throughput ELISA for human eosinophil peroxidase: a specific assay to quantify eosinophil degranulation from patient-derived sources. Journal of immunological methods. 2012;384:10-20

22. Rank MA, Ochkur SI, Lewis JC, Teaford HG, 3rd, Wesselius LJ, Helmers RA et al. Nasal and pharyngeal eosinophil peroxidase levels in adults with poorly controlled asthma correlate with sputum eosinophilia. Allergy. 2016;71:567-70

23. Trulson A, Nilsson S, Venge P. The eosinophil granule proteins in serum, but not the oxidative metabolism of the blood eosinophils, are increased in cancer. British journal of haematology. 1997;98:312-4

24. Slattery ML, Lundgreen A, Welbourn B, Wolff RK, Corcoran C. Oxidative balance and colon and rectal cancer: interaction of lifestyle factors and genes. Mutation research. 2012;734:30-40

25. Spessotto P, Dri P, Bulla R, Zabucchi G, Patriarca P. Human eosinophil peroxidase enhances tumor necrosis factor and hydrogen peroxide release by human monocyte-derived macrophages. European Journal of Immunology. $1995 ; 25: 1366-73$

26. Samoszuk MK, Nathwani BN, Lukes RJ. Extensive deposition of eosinophil peroxidase in Hodgkin's and non-Hodgkin's lymphomas. The American Journal of Pathology. 1986; 125:426-9

27. Samoszuk MK, Nguyen V, Gluzman I, Pham JH. Occult deposition of eosinophil peroxidase in a subset of human breast carcinomas. The American Journal of Pathology. 1996;148(3):701-6

28. Filaire E, Dupuis C, Galvaing G, Aubreton S, Laurent H, Richard R et al. Lung cancer: what are the links with oxidative stress, physical activity and nutrition. Lung cancer. 2013;82:383-9

29. Stresing V, Baltziskueta E, Rubio N, Blanco J, Arriba MC, Valls J et al. Peroxiredoxin 2 specifically regulates the oxidative and metabolic stress response of human metastatic breast cancer cells in lungs. Oncogene. 2013;32:724-35

30. Shen Z, Mitra SN, Wu W, Chen Y, Yang Y, Qin J et al. Eosinophil peroxidase catalyzes bromination of free nucleosides and double-stranded DNA. Biochemistry. 2001;40:2041-51

31. Ranguelova K, Chatterjee S, Ehrenshaft M, Ramirez DC, Summers FA, Kadiiska MB et al. Protein Radical Formation Resulting from Eosinophil Peroxidase-catalyzed Oxidation of Sulfite. The Journal of biological chemistry. 2010;285:24195-205 
32. Panagopoulos V, Zinonos I, Leach DA, Hay SJ, Liapis V, Zysk A et al. Uncovering a new role for peroxidase enzymes as drivers of angiogenesis. The international journal of biochemistry \& cell biology. 2015;68:128-38

33. Peterson CGB, Skoog V, Venge P. Human Eosinophil Cationic Proteins (ECP and EPX) and Their Suppressive Effects on Lymphocyte Proliferation. Immunobiology. 1986;171:1-13 